\title{
Exploration of Teaching Reform on Signals and Systems Course for Information Specialties
}

\author{
Kang Zhiwei \\ College of Computer Science and Electronic Engineering \\ Hunan University \\ Changsha 410082, China \\ hn_zwkang@126.com
}

\author{
Wu Jianhui \\ College of Computer Science and Electronic Engineering \\ Hunan University \\ Changsha 410082, China \\ wujianhui123@tom.com
}

\begin{abstract}
Signals and Systems" is the core and fundamental course of information specialties, playing a significant and supporting role in the whole system of specialized courses. Our university, dedicated to improving the teaching quality, gives top priority to construction on core courses. More efforts have been made to teaching reform on Signals and Systems, with the corresponding practice having been done. To resolve existing problems of teaching Signals and Systems in our university, measures for reform are brought up from such perspectives as teaching mode, teaching contents, experimental system and innovation application, which have obtained good effects in actual teaching practice.
\end{abstract}

Keywords—Signals and Systems; Course; Teaching; Reform

\section{INTRODUCTION}

The concepts of signals and systems arise in a wide variety of field, and the ideas and techniques with these concepts play an important role in such diverse areas of science and technology as communications, aeronautics and astronautics, circuit design, acoustics, seismology, biomedical engineering, energy generation and distribution systems, chemical process control, and speech processing[1]. The signals, which are functions of one or more independent variables, contain information about the behavior or nature of some phenomenon, whereas the systems respond to particular signals by producing other signals or some desire behavior.

"Signals and Systems", as the important basic course for information undergraduates, mainly includes the teaching of fundamental methods of signal transform and linear system analysis. It introduces the basic principles and techniques of signal processing from the fundamental ideas of signals and systems theory to real-world applications[2][3]. This course invites students to describe and solve two kinds of practical physical problems including signals and systems by a way of applying mathematical method.

"Signals and Systems" serves as the indispensable foundation for undergraduates to further learn the other courses, like communication, electronics, automation and computer, therefore, attracting increasing attention from teachers, students and teaching management departments. Consequently, what teachers engaging in teaching "Signals and Systems" always pursue is to explore teaching modes, research on teaching contents, build experimental system and create innovation application.

The research is funded by 2017 Hunan University Teaching Reform Project of Signals and Systems course for information specialties.

\section{EXISTING TEACHING PROBLEMS}

Due to the classic feature of basic specialized course-"Signals and Systems", orthodox teaching methods are difficult to meet new requirements as teaching specialized courses in modern information specialties develops. There is still a gap in the enhancement of discussion and exchange in the course of study, the improvement of students' hands-on capability in laboratory and innovation application. And main problems existing in teaching Signals and Systems are as below:

(1) The theory and method in this course covers the concepts of time domain and transform domain both of which are under complicated interconnection. If the clear-cut knowledge system fails to be established, confusion and puzzlement will generate in students themselves.

(2) Lack of close connection between theoretical teaching and practical teaching mainly manifests in deficiency of realtime correlation of classroom teaching and experimental link, which easily causes teaching content disconnect.

(3) There is shortage of enough interactivity in the classroom teaching, hard to mobilize students' learning interests and promote in-depth discussion and exchange among teachers and students.

(4) The limitation of teaching content leads to its less combination with practical application, which impedes students' progress towards innovation application in applying the related theory.

To resolve problems mentioned above and improve teaching quality, it is rather essential to further study all links of teaching "Signals and Systems" and explore new measures for teaching reform in a fine-grained way which would be applied to practical teaching.

\section{EXPLORATION OF TEACHING REFORM}

To work out problems existing in teaching "Signals and Systems”, several measures for teaching reform in every and each link have been put forward through all-round analysis from multiple perspectives. Specifics are as follows:

\section{A. Reform teaching mode}

A teaching mode, characterized by "a lecture-based large class and a discussion-based small class", will be adopted. The 
former focuses on teaching classroom knowledge to undergraduates of different small classes while the latter concentrates on panel discussion with the participation of each single small class. The better combination of lecturing and discussion will facilitate students learn and think independently in a flexible and effective way and try to analyze and solve problems, thereby, laying a solid foundation of professional theories and capabilities of innovation application for them. With a lecture-based large class complemented by a discussion-based small class in teaching "Signals and Systems", both parts constitute relatively complete curriculum teaching system, representing an optimized group of teaching mode.

\section{B. Enrich teaching content}

With a wide range of this course, due to its updated and advanced concepts and technologies, thus some important concepts and exercises of this course should be taught correlating with the latest research achievements except for teaching basic content. For example, illustrate new concepts and new algorithms of digital communication and smoothing in after-school exercises, or briefly introduce wavelet transform application in Fourier Transform exercise. In addition, teachers in the course of practical teaching can take into consideration their own results of research projects to discuss the living instances, which will intensify students' understanding of course knowledge.

\section{Build new experimental system}

The setup of experiment is of great significance for students to understand and consolidate the teaching content. In the teaching plan, experimental courses should be set consistent with the chapter layout and the teaching content. Moreover, experimental questions, including partly and comprehensive ones, should be designed elaborately for the purpose of catering for knowledge points of different levels, which will be conducive to the integration and comprehension of what students have learned. It generates good teaching effects as a complement. Furthermore, more attention should be paid to the integration of theory and practice for better teaching results. For instance, in the part of modulation and demodulation theory, a specified experiment should be arranged which aims at signal transmission and reception of communication system, helping deepen students' understanding of modulation and demodulation methods.

\section{Cultivate innovation and application ability}

As a core Information course, Signals and Systems' contents offer a study and research basis for many other disciplines, and are closely related to many courses. And this course is carried out based on such course knowledge as advanced mathematics, complex variable functions and integral transformation, as well as basis of circuit analysis. It builds a system model to process signals and analyzes the performance indexes of the system by time domain and frequency domain analysis, so as to construct the optimal signal processing system model, which can be applied to various fields. Therefore, students should be encouraged to conduct free exploration beyond classroom learning. They can apply joint use of what they have learned and knowledge about what they are concerned and interested, cultivate their innovative thinking and guide them to initially find and solve problems.

\section{E. Construct a course resources network platform}

As a professional basic course, "Signals and Systems" adopts the teaching mode of "a lecture-based large class and a discussion-based small class". Due to different learning foundation and level of students and rapid teaching process since the application of multimedia teaching, classroom teaching cannot ensure that every student will master main contents of each lesson. Therefore, building a teaching resources network on Signals and Systems can provide good interactivity. Through the platform, teachers can be informed of feedback from students timely, organize online answering, adjust teaching schedules and enhance teaching exchanges; meanwhile it's also convenient for teachers to post message and update contents on network, refine their teaching methods and schedules, solve students' doubts and questions in time and have conversation and exchanges so as to achieve interactive teaching between teachers and students.

\section{TEACHING REFORM PRACTICE}

Hunan University has attached great importance to teaching reform especially on core courses. Teaching reform on "Signals and Systems", the core course for Communication Engineering majors, has been steadily carried out and now it has been implemented in an all-around way, which has made prominent effects.

(1) Firstly, the reform on the teaching mode of lessons for large classes as the main part and discussions for small classes as the secondary part has been put into practice for over 6 years. Practice has proved that great progress has been achieved in course organization, discussion contents and innovative thinking, students' learning enthusiasm has also improved, and "Signals and Systems" has become one of their favorite curriculums. The teaching mode of combing lessons for large class and discussions for small class is good for students' self-learning and their thorough understanding of theories and application. Discussion for small class mainly adopts the student-centered and teacher-dominated teaching mode, which provides an excellent opportunity and platform for students to present themselves and to conduct academic discussions. Discussion in small class covers a wide range of topics. Both topics in theory and application aspects can arouse students' interests, stimulate fresh thinking, lead them to deeply understand, thoroughly grasp and flexibly uses the course knowledge, and equip themselves with solid foundation of professional knowledge and innovation and application ability.

(2) A key plan has been carried out in building the experiment course system, that is to extend single "verified" experiments to "verified", "research-based", "comprehensive" and "self-designed" experiment mode which is in gradual transition from one point to one aspect and finally to the whole area. This plan enriches the contents of experiment teaching. Besides, the experiment environment has been improved greatly. Along with experiment simulation based on MATLAB, the dedicated experiment box platform for course 
teaching is employed. The whole process, from collecting of typical signals to signal processing, can be conducted on the platform. The experiment topics are abundant and cover all knowledge points of the course. It also combines many signal processing applications in communication system, which helps students to link theory with practice and improve their capability to analyze and solve problems.

(3) Adjust teaching contents. Timely introduce scientific research practice into course teaching on the basis of correctly understand such dialectical relationships as between continuity and discretization, analysis and synthesis, classics and modernity, analytical methods and numerical methods, software simulation and hardware implementation. Contents of the course are adjusted according to the following characteristics: (1) The properties of continuous time and discrete time signals are explained with a number of numerical problems. The physical significance of different properties is explained using real-life examples[4]. In the process of signal and system analysis, highlight mathematical concepts, physical concepts and engineering concepts of Fourier transform, Laplace transform and $\mathrm{Z}$ transform and correspondingly reduce their mathematical techniques. (2) Reduce the traditional course linking between the Circuit Analysis course and the Signals and Systems course and optimize the transition process from the Signals and Systems course to the Digital Signal Processing course. (3) Combining classical theories with modern theories gradually shift some basic contents of the Digital Signal Processing course (such as DFT and DFS) to the Signals and Systems course. Meanwhile, appropriately add some modern signal processing teaching content to the course of Digital Signal Processing, draw up more engineering, design and comprehensive examples and exercises and put more weight on theoretical and engineering applications in regard to signal processing.

(4) The course resources network platform has been built and improved. Messages like course plans, teaching contents, experiment contents, discussion topics and assignments are released ahead on the network platform, and teaching materials and other related technical materials are offered in the network interactive system. In addition, a Q\&A discussion group for teachers and students has been created for convenient and timely discussion and solution to related questions of professional courses. As per teaching plans of "Signals and Systems" for different information majors in the university, network contents of Signals and Systems course are adjusted timely so as to adapt to the features of different information majors, provide targeted course teaching resources and reflect characteristics of all teaching stages.

(5) The scientificity of evaluation methods is of great importance to cultivate students' enthusiasm in study, correct learning ways and right attitudes towards exams. Meanwhile, evaluation results also reflect to some extent how well the teaching effect is and it can help us reformulate or adjust the reform scheme, functioning as a guidepost. A comprehensive evaluation mechanism is adopted which integrates classroom teaching, experiment teaching, small class discussion, assignments, mid-term exams and final exams. This mechanism puts more emphasis on stages of teaching and evaluates students in terms of their ability to master knowledge, ability to conduct experiments, ability to discuss questions, ability to answer exercises and comprehensive ability to answer questions, contributing them to meet needs of high qualified and professional talents.

(6) Independent innovation is not only the goal of in-depth study, but also ways to enhance capabilities of scientific research. In the practice of teaching reform, in addition to reforms in course contents and experimental contents, some practical problems in signal processing have also been added, with some of which coming from specific scientific research projects. Many of these problems are complicated and comprehensive. It is suggested to encourage some students to participate in teachers' research projects to stimulate their interest in learning and enthusiasm for scientific research and guide them to shape spirits of independent thinking and exploration via consulting references, discussing solutions, building system models, designing algorithms and simulating experiments, so as to enhance their capabilities of theoretical application and innovation.

\section{CONCLUSION}

"Signals and Systems" is a core basic course for information specialties, and the reform on its teaching is very significant. The concept of large class first and discussions for small class complementary, creating a complete course system and forming a good atmosphere of mutual learning, cooperation and research, joint discussion and common enhancement, is a good combination teaching mode. Enriching teaching contents by combining application needs can facilitate study effect and improve teaching quality. Completing experiment system is beneficial for students to enhance their manipulative ability and the habit of independent thinking and self-innovation. Impeccable resources course network platform serves as a basis of course teaching, which promotes interactive teaching and increase study efficiency.

In recent years, Hunan University's practice of teaching reform on Signals and Systems course has proved that good course teaching mode, well-chosen teaching and experiment contents, rich application fields and diversified solution thoughts are effective measures to arouse students' interests and enhance their ability of self-study and active innovation, which serves the purpose of achieving good teaching effect.

\section{REFERENCES}

[1] Alan V.Oppenheim, Alan S.Willsky and S. Hamid. Signals and Systems (Second Edition) [M]. Prentice Hall, 1996.

[2] Martin Vetterli, Jelena Kovačević, Vivek K Goyal. Foundations of Signal Processing (Third Edition) [M]. Cambridge University Press, 2014.

[3] Steven T. Karris. Signals and Systems: With MATLAB Computing and Simulink Modeling [M]. Orchard Pubns, 2008.

[4] Shaila Dinkar Apte. Signals and Systems: Principles and Applications [M]. Cambridge University Press, 2016. 